OPEN ACCESS

Approved by:

Frontiers in Systems Neuroscience

Editorial Office,

Frontiers Media SA, Switzerland

${ }^{*}$ Correspondence:

Gordon M. G. Shepherd

g-shepherd@northwestern.edu

Received: 24 September 2018 Accepted: 25 September 2018

Published: 18 October 2018

Citation:

Li X, Yamawaki N, Barrett JM, Körding KP and Shepherd GMG

(2018) Corrigendum: Scaling of Optogenetically Evoked Signaling in a Higher-Order Corticocortical Pathway

in the Anesthetized Mouse.

Front. Syst. Neurosci. 12:50.

doi: 10.3389/fnsys.2018.00050

\section{Corrigendum: Scaling of Optogenetically Evoked Signaling in a Higher-Order Corticocortical Pathway in the Anesthetized Mouse}

\author{
Xiaojian Li ${ }^{1}$, Naoki Yamawaki ${ }^{1}$, John M. Barrett ${ }^{1}$, Konrad P. Körding ${ }^{1,2,3}$ and \\ Gordon M. G. Shepherd ${ }^{1 *}$
}

${ }^{1}$ Department of Physiology, Feinberg School of Medicine, Northwestern University, Chicago, IL, United States, ${ }^{2}$ Department of Physical Medicine and Rehabilitation, Feinberg School of Medicine, Northwestern University, Chicago, IL, United States, ${ }^{3}$ Department of Bioengineering, School of Engineering and Applied Science, University of Pennsylvania, Philadelphia, PA, United States

Keywords: corticocortical, retrosplenial cortex, motor cortex, optogenetic stimulation, silicon probe

\section{A Corrigendum on}

Scaling of Optogenetically Evoked Signaling in a Higher-Order Corticocortical Pathway in the Anesthetized Mouse

by Li, X., Yamawaki, N., Barrett, J. M., Körding, K. P., and Shepherd, G. M. G. (2018). Front. Syst. Neurosci. 12:16. doi: 10.3389/fnsys.2018.00016

In the original article, there was a typographic error in Equation 2.

A correction has been made to the section MATERIALS AND METHODS, sub-section Model Based Analysis, paragraph 2, Equation 2:

$$
A_{M 2}(t)=\vartheta\left(m \sum_{\Delta t=1}^{T} e^{\frac{-\Delta t}{\tau_{\text {interact }}}} A_{R S C}(t-\Delta t)-\theta\right)+c
$$

The authors apologize for this error and state that this does not change the scientific conclusions of the article in any way.

The original article has been updated.

Conflict of Interest Statement: The authors declare that the research was conducted in the absence of any commercial or financial relationships that could be construed as a potential conflict of interest.

Copyright $\odot 2018$ Li, Yamawaki, Barrett, Körding and Shepherd. This is an open-access article distributed under the terms of the Creative Commons Attribution License (CC BY). The use, distribution or reproduction in other forums is permitted, provided the original author(s) and the copyright owner(s) are credited and that the original publication in this journal is cited, in accordance with accepted academic practice. No use, distribution or reproduction is permitted which does not comply with these terms. 